two small experimental reactors, Zeep and Ptr, were also in constant operation, and a new zero energy, heavy-water moderated reactor, $Z e d-2$, is being constructed and is nearing completion. One of the important lines of fundamental research carried out at Chalk River is the investigation of the structure of the atomic nucleus for which special facilities, such as the experimental reactors and particle accelerators, are provided. During the year under review major ancillary equipment was added to the $10-\mathrm{MeV}$. tandem accelerator for this particular investigation. In the Physics Division a new spectrometer, which employs the neutron beam from the $\mathrm{Nru}$ reactor as a probe to examine the forces holding together liquids and solids, was installed. The Research Chemistry Branch was mainly concerned with investigations on the breakdown of molecules exposed to intense radiation and the bombardment of metals with heavy ions. Fuel development, the physical properties of reactor materials, field tests of the method of disposal of fission products by fixing them in glass, and the development of new radiation monitoring instruments, including a tiny radiation detector which uses semiconductors, were some of the applied research problems investigated by the research establishment.

The directors and management of Atomic Energy of Canada Limited gave consideration during the year to the long-range expansion of research and development in the field of atomic energy, and recommended that Chalk River should not continue to expand, but that a new site should be selected at which future expansion could take place. In October 1959, the Government announced the establishment of a new research and development centre in Manitoba, on the east bank of the Winnipeg River between
Seven Sisters and Lac du Bonnet, to be known as the Whiteshell Nuclear Research Establishment. The first major facility to be provided at the new site is likely to be the Ocdre reactor. During October also, Canada and Euratom signed an agreement for co-operation in the peaceful uses of atomic energy and a technical agreement for a joint programme of research and development in heavy-water reactors. A group of Euratom industrialists visited Canada in the autumn to see the various atomic energy facilities. Close co-operation with the United Kingdom Atomic Energy Authority and the United States Atomic Energy Commission continued, as well as with the authorities in Australia, Japan and Pakistan. The number of staff from other countries attached to Atomic Energy of Canada Limited during the year was sixty-two, and was limited only because of lack of working and housing accommodation. The construction of the Canada-India reactor at Trombay, India, is now essentially complete and the initial start-up is scheduled for mid-1960.

The report concludes with the financial accounts of Atomic Energy of Canada Limited and with details of the Commercial Products Division which is responsible for the production, planning, processing and marketing of the radioisotopes produced in the Chalk River reactors. More than half the curies of radioantivity sold by Canada has been for the cobalt therapy machines for the treatment of cancer which were originally developed in Canada. One hundred and eighty-five machines have been installed in thirty countries. Another device recently developed is the Gammacell 220, which is a portable facility for the gamma-irradiation of materials, and fourteen of these units are in service in eight countries.

\title{
CONCENTRATION OF PLANKTON PIGMENTS IN AUSTRALIAN WATERS
}

$\mathrm{E}$ STIMATIONS of the quantity of plankton pigments are widely used as a measure of the biomass of phytoplankton. They have achieved this popularity through the ease and accuracy of the chemical estimation, and they give results more reliable than most other techniques. However, as G. F. Humphrey emphasizes in a recent paper issued by the Australia:st Commonwealth Scientific and Industrial Research Organization, they have many disadvantages. For example, there is a variable and uncertain relationship between pigments and the chemical composition of the organism, and so they are a poor measure of, say, the cellular carbon. Nevertheless, the pigments are the potential absorbers of the energy used in photosynthesis and the widespread usage of one particular method commends it further (Division of Fisheries and Oceanography. Technical Paper No. 9: The Concentration of Plankton Pigments in Australian Waters. Pp. 27. Melbourne: Commonwealth Scientific and Industrial Research Organization, 1960).

The author, Dr. G. F. Humphrey, who is chief of the Division of Fisheries and Oceanography, has gone to some length in perfecting a satisfactory modification of the Richards and Thompson technique for pigment measurements. He has also ascertained the precision obtained with the method, and for the analyses this amounts to \pm 10 per cent, but the variation between replicate plankton samples is much larger and particularly at greater depths it is shown even to exceed previous estimates of \pm 33 per cent.

The results described were obtained mainly from the Tasman Sea and in particular from two stations at 50 and $100 \mathrm{~m}$. depth off Sydney. The ratios of the pigments varied during the year, with either chlorophyll $a$ or $c$ predominating. Chlorophyll $c$ was frequently in excess and it appeared to be a pigment of major importance in the deeper waters. It should be mentioned, however, that the units used to express chlorophyll $c$ values cannot be compared in absolute terms with the milligrams of chlorophyll $a$, for the specific absorption coefficient of pure chlorophyll $c$ is not yet known and the determination of the actual weight of chlorophyll $c$ is therefore not possible.

No smooth seasonal variation is evident in the results, but from late winter to late summer there were a series of sharp increases in pigment. There is some evidence that these peaks may be correlated with the prevailing hydrological conditions. The depth distribution suggests that the inorganic 
phosphate content was inversely proportional to the chlorophyll, but neither nitrate nor total phosphate showed any correlation with the pigments.

The quantities of pigments found off Sydney covered the range found on more extensive cruises in the Coral and Tasman Seas and in the Indian Ocean. On these cruises the importance of chlorophyll $c$ was again evident.
The results described in this paper are the first detailed observations of plankton pigments from Australian waters, collected in the extensive oceano. graphical programme which the Commonwealth Scientific and Industrial Research Organization in Australia is now undertaking, and they form an interesting basis for comparison with other regions.

R. I. Currite

\section{CENOZOIC MAMMALS IN NORTH AMERICA}

\begin{abstract}
TST over one hundred yoars ago Charles Moore, an amateur geologist of Bath, washed and sieved three tons of clay to obtain 30 multicusped teeth : the clay was a Rhaeto-Liassic fissure infilling and the teeth were of Microlestes, and they remain to-day almost the only record of this rare group of animals astride the frontier that separates mammals and reptiles.

Despite this promising beginning, fow vertebrate palæontologists have taken to the labours of washing and sieving on a big scale. Jr. McKenna has been one and it has paid handsome dividonds; the washing and sieving of Wasatchian claystones and sandstones has yielded him 11,000 complete mammal teeth from a formation otherwise almost barron, and a horizon astride the Eocene and Palæocone all too poorly known. The complete dissociation of the remains is a considerablo limitation of the technique and Dr. M. C. MeKenna does not appear to have attempted any concentrating methods, the fossils being hand picked from sieved fractions (University of California Publications in Geological Scionces. 37, No. 1 : Fossil Mammalia from the Farly Wasatchian Four Mile Fauna, Eocene of Northwest Colorado. Pp. 1-130. (Berkeley and Los Angeles: University of California Press ; London: Cambridgo University Press, 1960.) 2.50 dollars).

A fauna of 58 species from 12 mammalian orders is described; these include four multituberculates, a marsupial, several primates and insectivores. 'The fauna shows close similarity with those of early Gray Bull fauna of Wyoming, though there aro notable
\end{abstract}

absentees, and is considered early Wasatchian, that is, basal Eocene. The paper has no plates, but the text.-figures are ample and exceptionally clear.

Pantodonta is an order of mammals the systematic study of which is fraught with difficulties; while distinction as an order is clear, the internal and oxternal affinities remain debatable. Rocent work by Dr. E. L. Simons is confined largely to the Palieocone species of North America, albeit this comprises most of the described forms; the European Eocene and Asiatic Oligocene forms are mentioned in his discussions (Trans. Amer. Phil. Soc. (New Scries), 50, Part 6: The Paleocene Pantodonta. Pp. 99. (Philadelphia: American Philosophical Society, 1960.) 2.50 dollars). Dotailed diagnoses are givon for North American Palwocene species only. The post-cranial skeleton is described for most genera where it is known, with differences noted, but few comments on their significance: although approximatoly half this paper is devoted to skeletal anatomy, there is only one illustration of pclves. The wealth of material available makes it difficult to accopt the quotation "thoy [Pantodonta] defy interpretation of their mode of life because they are so totally unlike anything now living"; they are no more remote than Titanotheres and mammal-liko roptiles.

Biostratonomic work threw little light on the cology of the pantodonts ; this is not surprising since their life habitat was probably quito different from their place of entombment. Concerning the relations to other orders, the author restates the main arguments used by earlier writors. R. J. G. SAVAGE

\section{EARTH SATELLITE OBSERVATIONS AND THE UPPER ATMOSPHERE}

\section{Temperature Inversion in the $\mathrm{Fl}$-Layer}

GUFFICIENTLY reliablo values of atmospheric $\$$ density-including the diurnal variations-in altitudes $200-700 \mathrm{~km}$. have been derived from the variations of the acceleration of artificial Earth satellites ${ }^{1-3}$. Measurements from rockets ${ }^{4,5}$ gave density values up to about $200 \mathrm{~km}$.

The densities obtained from rocket measurements and the satellite data could not be represented satisfactory by a single curve with monotonically varying gradient. Therefore, H. K. Kallmann ${ }^{6}$ suggested a modol which contains a 'wiggle' in the logarithmic density curve at altitudes $150-200 \mathrm{~km}$. It is model $C$ in her paper.

From the data ${ }^{7}$ from satollites $1958 \delta 2$ (Sputnik 3) and $1959 \zeta$ (Discoverer 6 ), it now became possible to derive the exact form of the 'wiggle'. Twenty values for atmospheric density at altitudes $180-235 \mathrm{~km}$. from the satellite $1959 \zeta$ and the numerous results from the satellite 195882 during August 1959-April 6, 1960 , were available for this purpose. During this period the altitude of the perigee of the latter satellite decreased from $215 \mathrm{~km}$. to $147 \mathrm{~km}$. In order to eliminate seasonal effects, only values with $|\Delta \delta|=$ $\left|\delta_{\pi}-\delta_{\odot}\right|<60^{\circ}$ were used (where $\delta$ is doclination, $\pi$ is perigee, $O$ is Sun).

The atmospheric densities were first derived according to a method described in detail in our earlier paper $^{1}$; that is, preliminary values for atmospheric density were computed using the scale heights of H. K. Kallmann's "preliminary model"'. Then a linear approximation to the logarithmic density curve was derived graphically for altitudes where the major air drag on the satellite oceurs. The gradient of this linear approximation was employed to dotermine the final atmospheric densities, so that we have an itera- 